\title{
Evidence for Shifting Connections during Development of the Chick Retinotectal Projection ${ }^{1}$
}

\author{
STEVEN C. MCLOON ${ }^{2}$ \\ Department of Anatomy, University of Minnesota, Minneapolis, Minnesota 55455
}

\begin{abstract}
The pattern in which optic axons invade the tectum and begin synaptogenesis was studied in the chick. The anterogradely transported marker, horseradish peroxidase, was injected into one eye of embryos between 5 and 16 days of development (E5 to E16). This labeled the optic axons in the brain. The first retinal axons arrived in the most superficial lamina of the tectum on E6. They entered the tectum at the rostroventral margin. During the next 6 days of development the axons grew over the tectal surface. First they filled the rostral tectum, the oldest portion of the tectum, and then they spread to the caudal pole. Shortly after the first axons entered the tectum on E6, labeled retinal axons were found penetrating from the surface into deeper tectal layers. In any given area of the tectum, optic axons were seen penetrating deeper layers shortly after arriving in that area. Electron microscopic examination showed that at least some of the labeled axons in rostral tectum formed synapses with tectal cells by E7. These results show two things which contrast with results from previous studies. First, there is no delay between the time the retinal axons enter the tectum and the time they penetrate into synaptic layers of the tectum. Second, the first retinotectal connections are formed in rostral tectum and not central tectum.
\end{abstract}

Retrograde tracing showed the first optic axons that arrived in the tectum were from ganglion cells in central retina. Previous studies have shown that the ganglion cells of central retina project to the central tectum in the mature chick. This opens the possibility that the optic axons from central retina, which connect to rostral tectum in the young embryo, shift their connections to central tectum during subsequent development. As they enter the tectum the growth cones of retinal axons appear to be associated with the external limiting membrane. During the time that connections would begin to shift in the tectum a second population of axons appears at the bottom of stratum opticum, some with characteristics of growth cones. This late-appearing population may represent axons shifting their connections.

These results have implications for theories on how the retinotopic pattern of retinotectal connections develops.

Received October 25, 1984; Revised March 25, 1985;

Accepted March 27, 1985

${ }^{1}$ I wish to thank Ms. Kate Edson and Ms. Lenore Mottaz for technical assistance. This work was supported by grants EY05371 and EY05372 from the National Institutes of Health.

${ }^{2}$ Correspondence should be addressed to Department of Anatomy, University of Minnesota, 4-135 Jackson Hall, 321 Church Street S.E., Minneapolis, MN 55455.
Previous studies in developing chick have shown that retinal axons arrive at the tectum, a primary termination site for these axons, grow over the tectal surface, and after a delay of several days, penetrate into deeper tectal layers (Crossland et al., 1975). This study suggested that the first retinal axons entering the tectum come from central retina and that they first penetrate into synaptic layers in central tectum. This would be consistent with the pattern of retinotectal connections seen in the mature chick. In the adult the spatial order of the retinal ganglion cells is preserved in their pattern of connections with the tectum such that central retina projects roughly to central tectum (DeLong and Coulombre, 1965; McGill et al., 1966; Crossland and Uchwat, 1979). This projection pattern is typically described as retinotopic.

Sperry (1963) first proposed the theory of chemospecificity as a possible mechanism for the development of the retinotopic pattern of connections. This theory suggests that fixed cytochemical markers are present on retinal axons and tectal cells, and a matching of the markers in the two populations would generate the orderly map. The data of Crossland et al. (1975) give considerable support for the chemospecificity theory. If axons from central retina grow over uninnervated regions of the tectum to penetrate the synaptic layers in central tectum, it suggests that these axons seek out the appropriately marked tectal cells with which to form initial connections.

Considerable evidence shows that in fish and frogs there is a continual making and breaking of connections as retinal axons grow across the tectum. These species have a prolonged free swimming development with functional retinotectal connections. These connections are retinotopically organized before the entire retina or tecturn is generated. In these species there is a disparity of growth between the retina and tectum. The retina develops in a central-toperipheral fashion with newly generated cells added to the periphery. The tectum develops in a rostral-to-caudal fashion with newly gen erated cells located around the caudal pole of the tectum. Gaze et al. (1974) were the first to point out this disparity, and they hypothesized that retinal terminals in the tectum would have to shift as new retinal axons arrive in order to maintain the orderly retinotopic map. Although this hypothesis has aroused some controversy, the evidence supports the existence of shifting connections in these species. (See Easter and Stuermer (1984) and Reh and ConstantinePaton (1984) for a more comprehensive discussion of these studies.)

A disparity exists in the pattern of development of the chick retina and tectum. The chick retina develops in a central-to-peripheral fashion (Fujita and Horii, 1963; Goldberg and Coulombre, 1972; Kahn, 1973, 1974; Dutting et al., 1983), whereas the tectum differentiates in a rostral-to-caudal pattern (LaVail and Cowan, 1971a, b; Rager, 1980). This opens the possibility for shifting connections in this species as well. If this were the case, the chemospecificity hypothesis would be much less tenable. However, chicks are not 
free living or foraging animals during the time that their visual system develops. In this species there is no apparent behavioral value for retinotectal connections to develop before most axons are in place. Since the previous studies which examined the development of the chick visual system used relatively insensitive techniques, it was not possible to say definitively which of these two alternative approaches is used by the chick.

The present study re-examines the development of the retinotectal connections in the chick. This study attempts to determine whether retinotectal connections shift during development or if axons form their first connections at the tectal locus appropriate for the mature chick. A preliminary account of this study appeared previously (McLoon, 1982a).

\section{Materials and Methods}

Fertilized chicken eggs (pathogen-free White Leghorn crossed with Rhode Island Red) obtained from the University Poultry Center were incubated in an egg incubator at $37^{\circ} \mathrm{C}$. After 3 days of incubation the embryos were removed from the shell and transferred to embryo culture chambers (Dunn and Boone, 1976). The cultured embryos were maintained in a forced draft tissue culture incubator at $37^{\circ} \mathrm{C}, 95 \%$ relative humidity and $1 \% \mathrm{CO}_{2}$. A total of 140 embryos were used in this study.

In order to study the central distribution of retinal axons in the brain of these early embryos it was first necessary to determine the best anterograde tract tracing technique. It was necessary that the technique used be extremely sensitive, so as to distinguish even small projections, that the tracer diffuse readily in the eye (the injection site), so as to label the entire projection of that eye, and that the tracer not exhibit significant transcellular transport in the brain during the postinjection survival time needed to label the entire projection.

In a previous study this laboratory was unable to identify definitively the ipsilateral retinofugal projection in the developing chick using the anterograde transport of tritiated amino acids coupled with autoradiography (McLoon and Lund, 1982). Since this projection was readily identified using other anterograde trace tracing methods, this technique was ruled out for the present study as not being suitably sensitive. The following two anterograde tracers were tested for the criteria listed above: horseradish peroxidase (HRP) $(30 \%)$, from Boehringer-Mannheim in 2\% dimethylsulfoxide (DMSO) and saline), and wheat germ agglutinin conjugated to HRP (WGA-HRP) (1\%, from Sigma in saline). Embryos were selected which would be 10 days of incubation (E10) at the time of perfusion. At 1.5, 3, 6, 9, 12, 15, or $24 \mathrm{hr}$ before the lime of perfusion an embryo received a $2-\mu$ l pressure injection of one of the tracer substances into the right eye via a fine pulled glass pipette. Embryos were perfused through the left ventricle with $0.5 \%$ glutaraldehyde in phosphate buffer followed by $2 \%$ buffered glutaraldehyde, and were staged according to the method of Hamburger and Hamilton (1951). The brains were removed from the skull, post-fixed for $2 \mathrm{hr}$ in cold $2 \%$ buffered glutaraldehyde, and placed overnight in $20 \%$ sucrose in phosphate buffer at $4^{\circ} \mathrm{C}$. Tecta contralateral to the injected eyes were removed and frozen sectioned at $40 \mu \mathrm{m}$. The tecta were oriented so that their long axis was in cross-section or longitudinal section. Every third section was mounted on a chrome-alum/ gelatin-coated slide and air dried. The slides were reacted with tetramethylbenzidine (TMB) and hydrogen peroxide (Mesulam, 1978), counterstained with thionin and coverslipped (Adams, 1980). The chromogen, diaminobenzidine (DAB), was tried in place of the TMB, however, this reaction worked poorly on mounted tissue sections and, therefore, was not used routinely. As detailed under "Results," HRP alone was determined to be the best tracer for the present needs.

The distribution of retinal axons in the tectum was examined in embryos from $\mathrm{E} 5$ to $\mathrm{E} 16$. Embryos received a 0.5 - to $2-\mu$ injection of $\mathrm{HRP}$ in the right eye as described above. Embryos younger than E7 were immersion fixed after $9 \mathrm{hr}$ post-injection survival and embryos E7 and older were perfused after $15 \mathrm{hr}$. The embryos were processed as described above. The only exception was that the whole head of embryos younger than E8 was sectioned rather than just the tectum.

Uninjected embryos at each age of development and embryos which received the HRP injection into the forebrain were processed in the same manner to serve as controls. This was to rule out the presence of endogenous peroxidase or the nonspecific transport of HRP, possibly through the vasculature. Peroxidase-positive reaction product was not encountered in the superficial layers of the tectum in any of these cases. It was concluded that any label present in the superficial layers of the tectum in the experimental animals was the result of axonal transport of HRP injected into the eye.
The distribution of retinal axons in the tectum of these embryos was analyzed as follows. For each section the outline of the tectum contralateral to an injected eye was drawn on paper with an X-Y plotter attached to the microscope stage under brightfield illumination. The borders between the tectal laminae were also indicated on the plot. Then illumination was switched to polarized light and the distribution of the TMB reaction product was plotted on the same drawing with different colored ink. Next, using a Bioquant image analysis system, the outline of the surface of each tectum section was replotted as a straight line with the distribution of label in the different layers indicated on the line. Alignment of the serial plots gave a flat representation of the entire tectal surface showing the position and depth of penetration of the retinal axons. The outline of the tectum and the position of the label were smoothed by an artist with a french curve, producing maps like those illustrated in Figure 1.

Electron microscopy was used to determine the nature of the interaction between the retinal axons and tectal cells. The right eyes of E6, E7, and E8 embryos were injected with HRP as described above. Twenty-four hours later, these embryos were perfused with $0.1 \mathrm{M}$ cacodylate buffer followed by $2 \%$ glutaraldehyde, $2 \%$ paraformaldehyde, $0.5 \%$ acrolein, and $0.5 \%$ DMSO in cacodylate buffer. The tecta contralatcral to the injected eyes were dissected and placed in fixative for another $2 \mathrm{hr}$. These were rinsed in buffer, embedded in agar, and sectioned at $100 \mu \mathrm{m}$ with a Vibratome. The sections were collected in buffer, incubaled in DAB and hydrogen peroxide, and stored at $4^{\circ} \mathrm{C}$ overnight. The tissue was osmicated, dehydrated in a graded series of ethanols, and embedded in Spurrs media (from Polysciences Inc.). Thin sections were cut trom these blocks such that the tectum could be examined through its entire thickness from internal to external limiting membrane. Sections, either unstained or stained with uranyl acetate and lead citrate, were examined and photographed with a JEOL $100 \mathrm{CX}$ electron microscope.

Retrograde tract tracing techniques were employed to identify the retinal ganglion cells which give rise to the earliest tectal projection. Embryos on their fourth day of incubation, a time prior to axonal ingrowth into the tectum, were injected with a retrograde fluorescent tracer along the rostroventral border of the tectum. Injections were made tangentially along this border to ensure that the maximum number of retinal axons entering the tectum would be labeled. The tracers used were True Blue (TB) ( $5 \%$, from Sigma in saline), Fast Blue (FB) (2\%, from Sigma in saline), 4-acetamido, 4-isothio-cyanostilbene-2,2-disulfonic acid (SITS) (10\%, from Chemalog in saline), or rhodamine isothiocyanate (RITC) ( $2 \%$, from Sigma in $2 \%$ DMSO and saline). Between $\mathrm{E} 5$ and $\mathrm{E} 8$ the retinas contralateral to the injected tecta were fixed in $4 \%$ paraformaldehyde and flat mounted onto glass slides. These were examined with a Leitz Dialux epifluorescent microscope. The distribution of labeled cells across the retinas was plotted with an $X-Y$ plotter attached to the microscope stage. As a control, some embryos received the injection in forebrain or metencephalon rather than tectum but were otherwise processed identically. No retinal ganglion cells were ever labeled by these control injections.

\section{Results}

\section{Tracer selection}

There were significant differences in the pattern of anterogradc labeling of the central visual pathways seen with the different tracers. With HRP injected intraocularly in the E10 embryo, the entire retinal projection appeared to be well labeled by $9 \mathrm{hr}$ of postinjection survival time. Longer survival times did not result in a larger distribution of labeled axons, nor was any spread of label into tectal cells apparent. With shorter survival times local unevenness was seen in the density and distribution of labeled axons in the tectum. HRP met our criteria and was selected as the most advantageous tracer for this study.

In contrast to the results obtained with straight HRP, the WGAHRP results were much more difficult to interpret. Although the basic pattern of axonal labeling in the tectum was similar to that seen with HRP, with WGA-HRP there was an ever increasing distribution of label in the brain with increased survival time. This increased labeling with longer survival time was primarily due to labeling of tectal cells, particularly the radial glia. Thus, there appears to be significant leakage of the WGA-HRP from the retinal axons into the brain. A sirrilar conclusion was reached by other investigations (Gerfen et al., 1982). Due to the potential for leakage of label, WGA-HRP was 
not selected as the tracer for the bulk of this study. An interesting side feature of the tracer was that, with very short survival times, i.e., 1 to $1 \frac{1 / 2}{h r}$, only a small discrete group of axons was labeled from the injection site in the retina into the central visual nuclei. This laboratory has recently made use of this technique for mapping the topography of the early projection in the optic nerve and tract (S. C McLoon, manuscript in preparation).

\section{Development of retinal innervation to the tectum}

The retinal innervation of the tectum was studied by labeling the axons with intravitreal injections of HRP and examining the distribution of HRP-labeled axons in embryos at successive ages between $\mathrm{E} 5$ and $\mathrm{E} 16$. Although there was a continuous series of changes in the pattern of innervation with each additional day of development, the general nature of these changes can be more easily illustrated by describing the changes seen over a several-day period. The following description is broken into four time periods which should not be misconstrued as discrete slages. ${ }^{3}$

Embryonic days 5 and 6 . On E5 a significant number of axons had exited the eye. These axons ran just inside the external limiting membrane on the ventral side of the optic stalk. Many axons extended through the chiasm into the contralateral optic tract. Some labeled axons were also seen coursing into the optic tract ipsilateral to the injected eye at the chiasm. The ipsilateral projection has been described more fully in previous papers (McLoon and Lund, 1982; O'Leary et al., 1983; Thanos and Bonhoeffer, 1984). By late E6 the first labeled axons were visible on the rostroventral pole of the contralateral teclum (Fig. 1). The axons entered the tectum running parallel to the tectal surface just inside the external limiting membrane in lamina ii. (The laminar designations for the developing tectum used throughout this paper conform to those described by LaVail and Cowan (1971a).) Labeled axons were encountered at this age coursing from lamina ii into the adjacent lamina i. Many of these axons appeared to arborize in lamina i (Fig. 2).

Embryonic days 7 to 9 . During this period the retinal axons continued to spread over the surface of the rostral tectum. By E9 the entire rostral tectum contralateral to an injected eye was covered by labeled retinal axons (Fig. 1). The caudal tectum remained uninnervated by retina. The axons grew across the surface of the tectum in the most superficial layer. Shortly after axons arrived in any given region of the tectum, they turned perpendicular to the tectal surface and penetrated to deeper layers. This is illustrated for an $\mathrm{E} 9$ embryo in which labeled retinal axons were not yet present in the dorsal or caudal tectum (Fig. $3 B$ ), were present only in lamina $x$, the most superficial layer, in mid-tectum where they had just arrived (Fig. $3 C$ ), and were present in laminae ix and $x$ of rostroventral tectum where they first entered the tectum (Fig. $3 D$ ).

Embryonic days 10 to 12 . Over this 3-day period the invasion of the tectum by retinal axons advanced caudally until the entire tectal surface was covered by axons (Fig. 1). As in the earlier ages, labeled retinal axons first appeared in previously uninnervated regions of the tectum in the most superficial lamina (Fig. 4B). Almost immediately after entering a tectal region they penetrated into the next deeper layer (Fig. 4C). During this same period labeled retinal axons in the rostral tectum penetrated into deeper laminae, and judging from the density of the label, they ramified extensively in certain of these laminae. For example, in E10 embryos labeled axons were seen in the rostroventral tectum from superficial lamina xii down to lamina viii (Fig. 4D). In this region of the tectum the label was heavy in

\footnotetext{
${ }^{3}$ During chick development the tectum undergoes a rotation such that the original caudal pole comes to lie dorsally and the rostral pole moves ventrally. This paper will use "caudal pole" to refer to the end of the tectum which was originally in the caudal position regardless of its actual position at any particular point in development. Similarly, "rostral," "dorsal," and "ventral" will refer to pre-rotation positions. For more information on the rotation of the tectum see Goldberg (1974).
}

laminae $x i$ and $x$, suggesting extensive arborizations. In more caudal regions of the tectum the retinal axons had not penetrated as deeply.

Embryonic days 13 to 15 . The relinal axons penetrated into deeper tectal layers during this period of development, so that by E15, labeled axons were present from lamina $x v$ into lamina viii (Fig. 5). This was also a "period of equalization" during which the rostralcaudal gradation in the depth of retinal axon penetration disappeared. By E15 the depth of penetration of labeled retinal axons was nearly the same in all areas of the tectum. Based on the density of label, the heaviest arborization of retinal axons was in laminae xiv, $x$ iii, $x$, and $x$.

\section{Ultrastructure of retinotectal contacts}

HRP-labeled retinal axons lying adjacent to the tectal surface were readily identificd with the clectron microscope. The HRP was evident in the axons as electron-dense vesicles. At all three ages, E7 to E9, labeled axons were found turning perpendicular to the tectal surface and entering deeper tectal layers. HRP-labeled profiles were present adjacent to the dendrites and somas of tectal cells. Often, synapselike junctions were encountered between labeled retinal processes and tectal cells. In the best case these junctions had a cluster of spherical vesicles in the HRP-labeled presynaptic profile and a distinct membrane density (Fig. 6, $A$ and $B$ ). In general, junctions encountered in E8 and E9 embryos had better developed membrane densities and more vesicles than were found in E7 embryos. It was common, however, for either the vesicles or membrane density to be absent (Fig. 6, $C$ and $D$ ). Without an analysis of serial sections, it was not possible to tell whether the missing vesicles or membrane density were present out of the plane of section. Synaptic junctions of both axosomatic and axodendritic types were present, but the latter was most common. In some cases an en passant junction was formed from a swelling off an HRP-labeled axon (Fig. 6E). In $E 7$ and E8 embryos, all of the HRP-labeled axons present in the most superficial layer of the rostroventral tectum were running parallel to one another and to the tectal surface. On E9, labeled axons appeared running approximately perpendicular to the mass of axons yet still parallel with the tectal surface (Fig. $6 F$ ). This late-appearing population was generally mixed with the original axons but positioned at the deepest extent of this group. Some of these processes had characteristics of growth cones which include the presence of many vesicles, numerous filopodia, and few microtubules.

\section{Earliest projecting ganglion cells}

Retrograde transport of fluorescent dyes was used to identify the ganglion cells giving rise to the first retinal axons which entered the tectum. Fluorescent dyes were injected into the tecta before the arrival of retinal axons, and the retinas were then examined for labeled ganglion cells just after the first retinal axons arrived in the tectum. The fluorescent dyes TB, FB, and RITC gave similar results in terms of the distribution of labeled ganglion cells in the retiria. No labeled cells were ever found with SITS. Usually, more labeled cells were found with FB than with the other dyes. For this reason the following data refer exclusively to studies using FB. With dye injections into the tectum on $\mathrm{E} 4$, no retrogradely labeled cells were found in the contralateral retina on E5 or E6. Since the anterograde HRP study clearly shows retinal axons entering the tectum on E6, it was somewhat surprising that retinal ganglion cells could not be retrogradely labeled at this age. The lack of retrograde label at this age may be due to an additional time required for the label to be picked up by the axons entcring the tectum and transported back to the cell body. By E7, a cluster of ganglion cells just dorsal-nasal to the optic fissure was labeled. Early on E7 there were typically about 40 labeled cells per retina (Fig. $7 A$ ). By $E 8$ the area of the retina containing labeled cells had increased slightly but was still centered around a point dorsal-nasal to the optic fissure. There was also an increase in the concentration and number of labeled cells at this age, with 160 per retina being typical (Fig. 7B). 

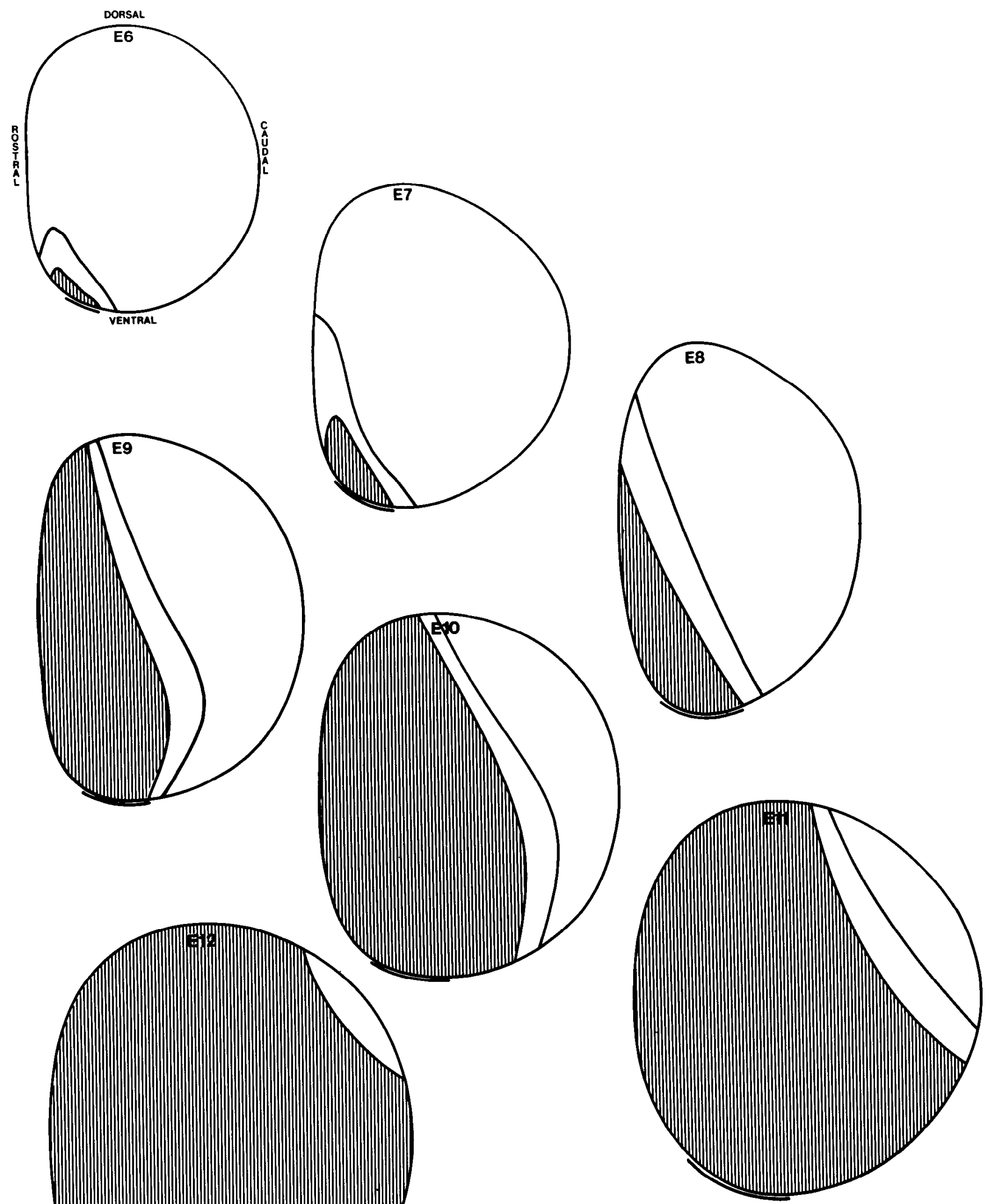

Figure 1. Reconstructions from serial sections showing the invasion of retinal axons (solid line) across the tectal surface in embryos from day 6 of incubation $(E 6)$ to day $12(E 12)$. On E6 the first retinal axons enter the rostroventral tectum. From E7 to E9 the projection fills the rostral tectum. From E10 to $\mathrm{E} 12$ the retinal axons grow toward the caudal pole of the tectum. The shaded area represents axons penetrating below stratum opticum into deeper tectal layers. The axons appear to penetrate any given region shortly after arriving in that region. 

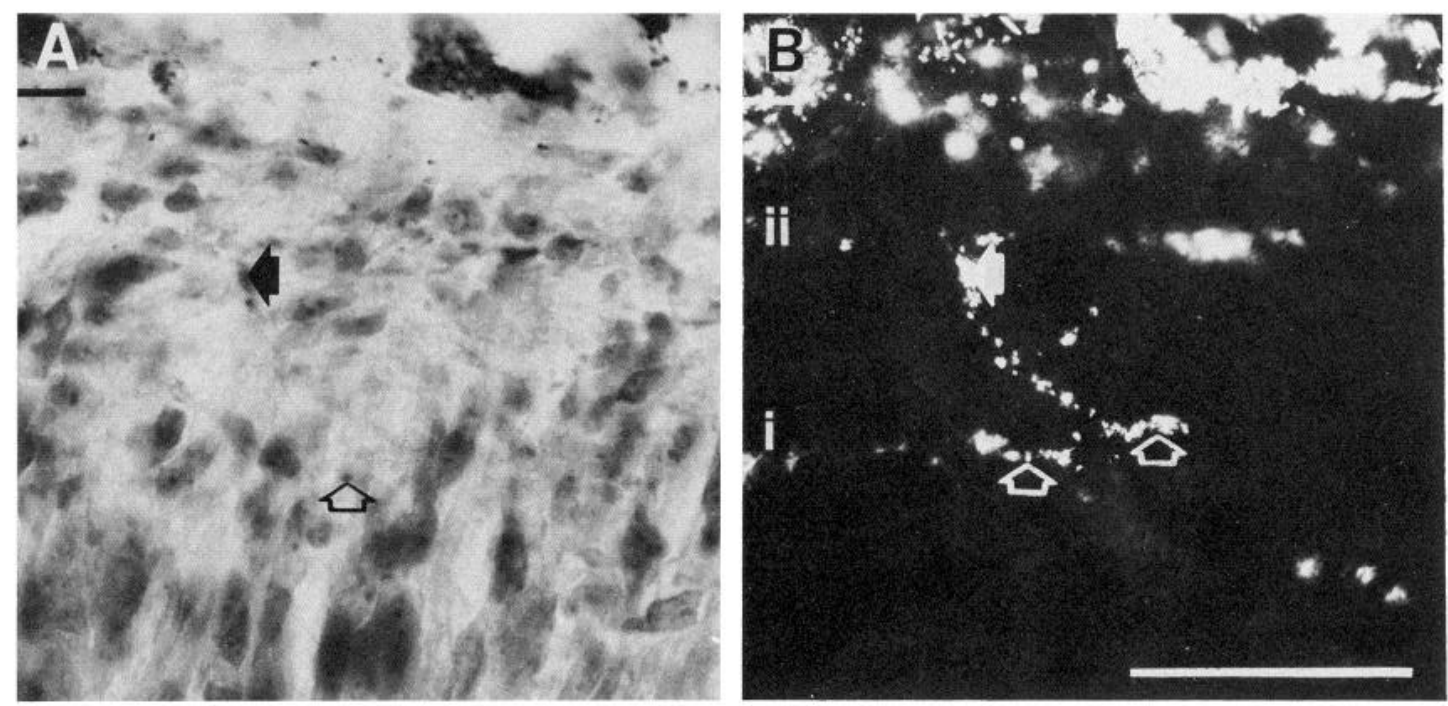

Figure 2. Brightfield $(A)$ and darkfield $(B)$ photomicrographs of the rostroventral tectum of an E6 embryo. The first retinal axons, which have been labeled with HRP, have entered the tectum in lamina ii. One axon has turned perpendicular to the tectal surface (bar), leaving lamina ii (open arrow) and arborizing in lamina i (solid arrow). The bar in $B$ indicates $25 \mu \mathrm{m}$.

\section{Discussion}

This study describes the development of the retinal innervation of the tectum in chick embryos. The projection of the retina onto the tectum was demonstrated by the anterograde transport of intraocularly injected HRP. The development of this projection was examined in embryos from 5 to 16 days of incubation (E5 to E16). These data were analyzed relative to four main questions. First, what is the pattern of retinal axon invasion over the surface of the tectum? Second, what is the pattern of penetration of retinal axons into the synaptic layers across the tectum? Third, at what point in development do retinal axons begin to make synapses in the tectum? Fourth, where are the ganglion cells located in the retina which give rise to the first axons which enter the tectum?

The first retinal axons enter the tectum on $\mathrm{E} 6$ at its rostroventral margin. From E6 to E9 the projection fills the rostral pole of the tectum. From E9 to E12 the projection expands caudally to cover the entire tectal surface. These results obtained with the anterograde transport of HRP confirm the pattern of invasion as determined with other anterograde transport techniques (Crossland et al., 1975; Thanos and Bonhoeffer, 1983; Fujisawa et al., 1984) and with reduced silver techniques (DeLong and Coulombre, 1965; Goldberg, 1974). There is a polarity of cell genesis and maturation in the tectum such that the rostral pole is the earliest to develop and the caudal pole is the last to develop (LaVail and Cowan, 1971a, b; Rager, 1980). Thus, it appears that the retinal axons initially cover the most mature portions of the tectum before extending onto more recently added portions. In primary cultures derived from early developing chick visual system, retinal axons grew onto a substrate of rostral tectal cells in preference to a substrate of caudal tectal cells (Bonhoeffer and Huf, 1982). This selectivity of retinal axons for more mature tectum observed in vitro appears to reflect a phenomenon which occurs in vivo as well. These results suggest that a cell surface marker or substrate cue to which the retinal growth cones have an affinity may be produced by tectal cells in an age-dependent fashion.

As soon as the first labeled axons were detected in the rostroventral tectum on E6, individual axons could be seen leaving the stratum opticum and arborizing below it. At later ages a short front of advancing axons was confined to stratum opticum followed by axons penetrating into the deeper tectal layers. The overall pattern of penetration begins in rostroventral tectum and proceeds toward caudodorsal tectum. Up to E15, the most advanced penetration of retinal axons was always in the rostroventral tectum. The results of Crossland et al. (1975) suggested that the first retinal axons delayed penetration below stratum opticum for 2 days after entering the tectum. It was also suggested that the site of the first retinal axon penetration below stratum opticum was in central tectum rather than in rostral tectum, as the present findings indicate. In the earlier study, tritiated proline was injected into the eye, and the brain was processed for autoradiography. In young chick embryos autoradiographs have a high background with this technique which might obscure smaller projections. The anterograde transport of HRP appears to be a more sensitive technique for tracing axonal projections in early embryos than was available to earlier investigators. The Golgi stain applied to the early chick tectum also revealed axons which may have been retinal in origin, penetrating below stratum opticum without a delay (Rager and von Oeynhausen, 1979). This further supports the HRP results.

At least some of the axons in the early tectum which penetrate below stratum opticum are forming synapse-like contacts. As early as E7 in the rostral tectum, HRP-labeled retinal axons were identified containing aggregations of vesicles. These vesicle aggregations were frequently adjacent to processes of tectal cells containing a membrane density. McGraw and McLaughlin (1980) also observed synaptic contacts in rostral tectum of E8 chicks. They concluded that these were retinal in origin since many were eliminated with early enucleations. These same investigators reported a rostralcaudal gradient in the appearance of synapses in the tectum. This conforms to the pattern of tectal neurogenesis and maturation and penetration of retinal axons into the synaptic layers. Synaptic transmission from retinal fibers in the tectum has been recorded as early as E10 (Rager and Kreische, 1978). Since the most rostral and ventral portions of the tectum are not readily accessible in the early embryo, one might suppose that in this study the electrodes were placed in central or caudal tectum. It seems quite likely that synaptic activity is possible in the more mature rostral tectum even before E10. Thus, the early synapses seen in the rostral tectum of E7 to E9 embryos may be functional.

Axons from ganglion cells in the central retina are the first to reach the tectum. Retrograde tracers were employed to identify the retinal ganglion cells which formed the earliest projection to the tectum. The first ganglion cells labeled by massive injections into the tectum were all positioned in central retina dorsal-nasal to the optic fissure. This is also the area where the first ganglion cells withdraw from the mitotic cycle (Fujita and Horii, 1963; Kahn, 1973, 1974; Dutting et 

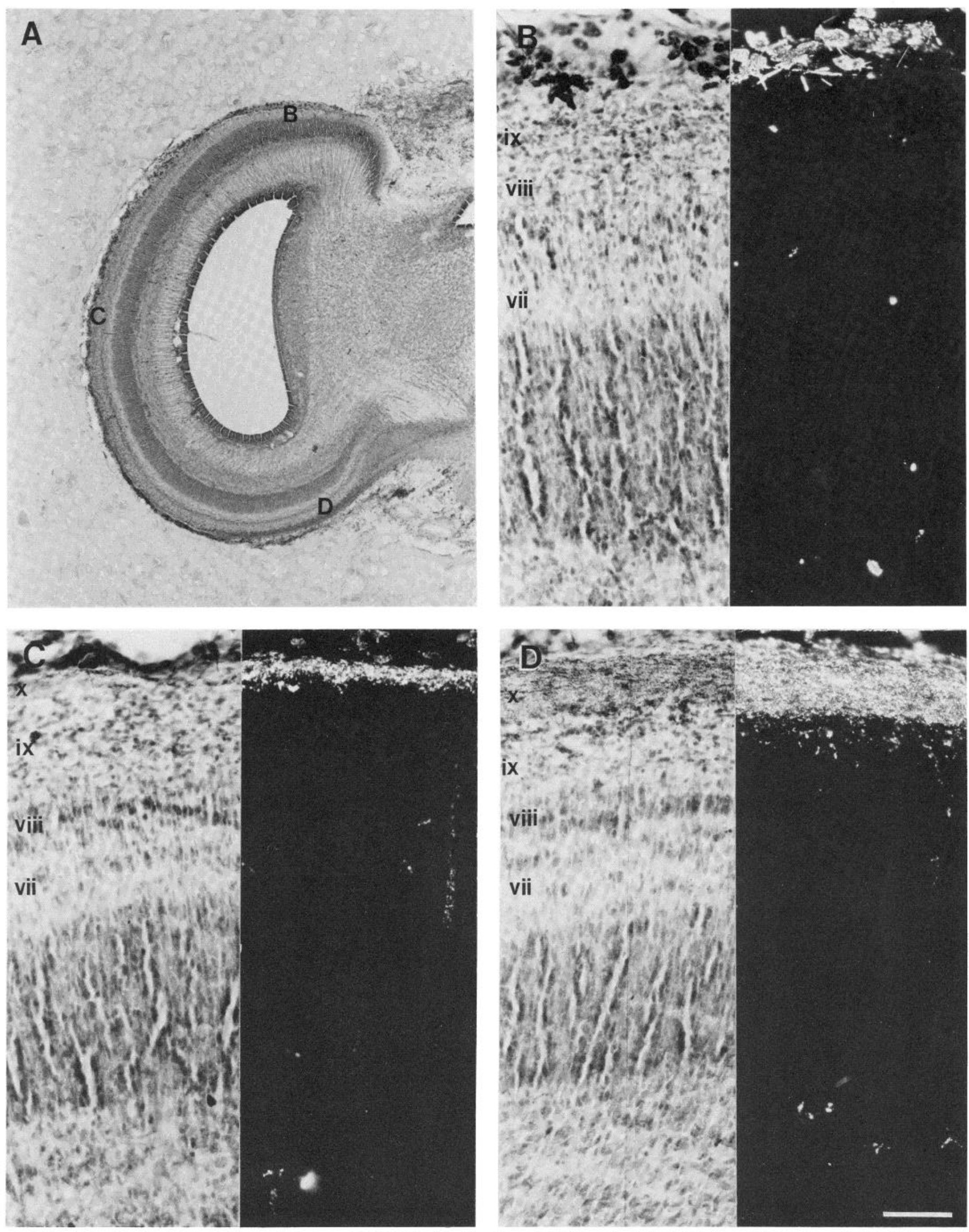

Figure 3. A, Low power photomicrograph of a cresyl violet-stained section through the long axis of the tectum from an E9 embryo. $B$ to $D, H i g h e r$ power brightfield and darkfield photomicrographs, approximately from the areas indicated in $A$, showing the HRP-labeled axons. $B$, Retinal axons have not yet reached caudal tectum. $C$, In mid-tectum, retinal axons have arrived in lamina $x . D$, In rostral tectum retinal axons have arrived in lamina $x$ and penetrated into lamina ix. Bar, $50 \mu \mathrm{m}$. 

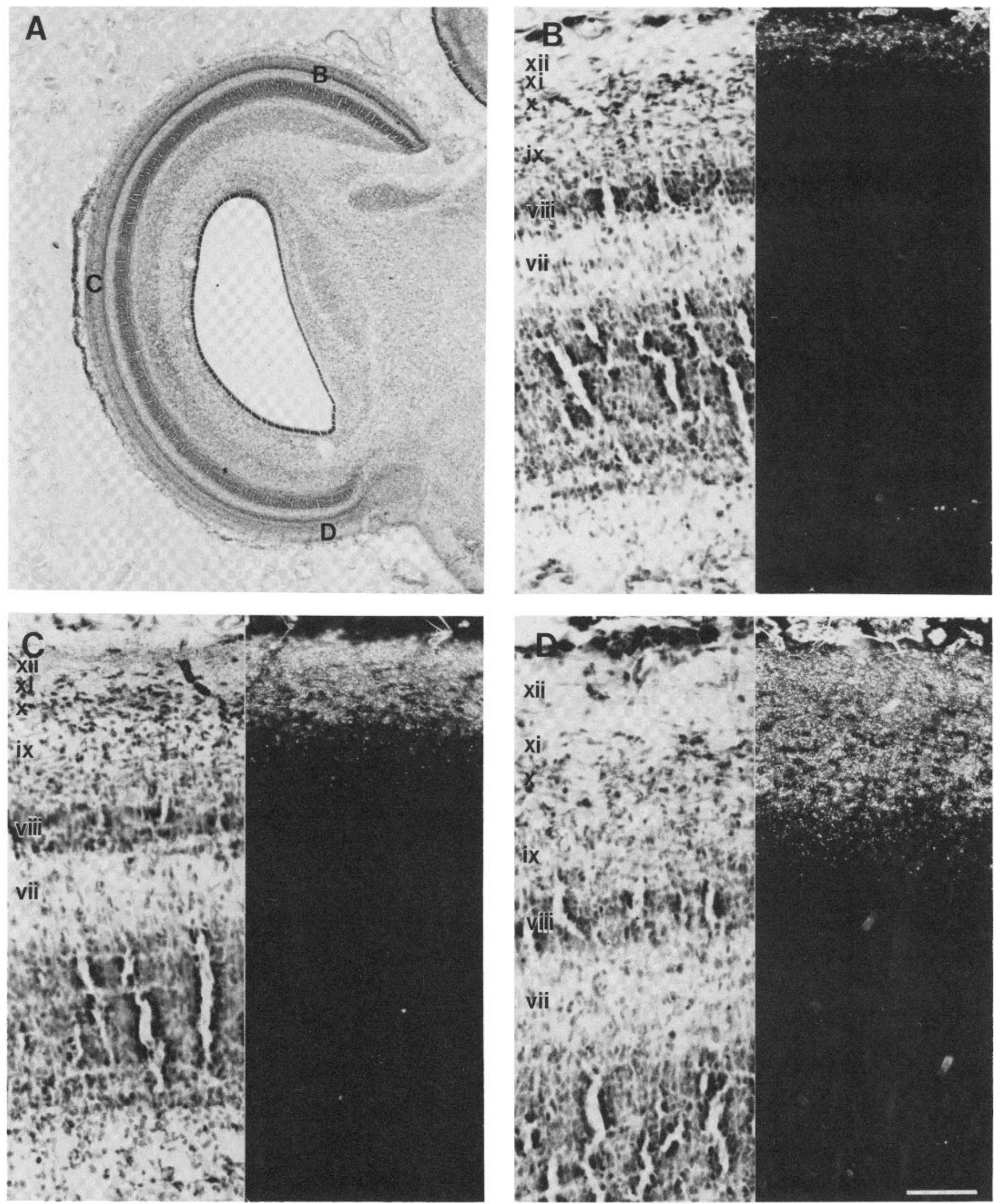

Figure 4. A, Low power photomicrograph of a cresyl violet-stained section through the long axis of the tectum from an E12 embryo. $B$ to $D$, Higher power brightfield and darkfield photomicrographs, approximately from the areas indicated in $A$, showing the HRP-labeled axons. It shows that retinal axons have penetrated the deepest into the synaptic layers in rostral tectum $(D)$ and have penetrated the least in caudal tectum $(B) . B a r, 50 \mu \mathrm{m}$. 

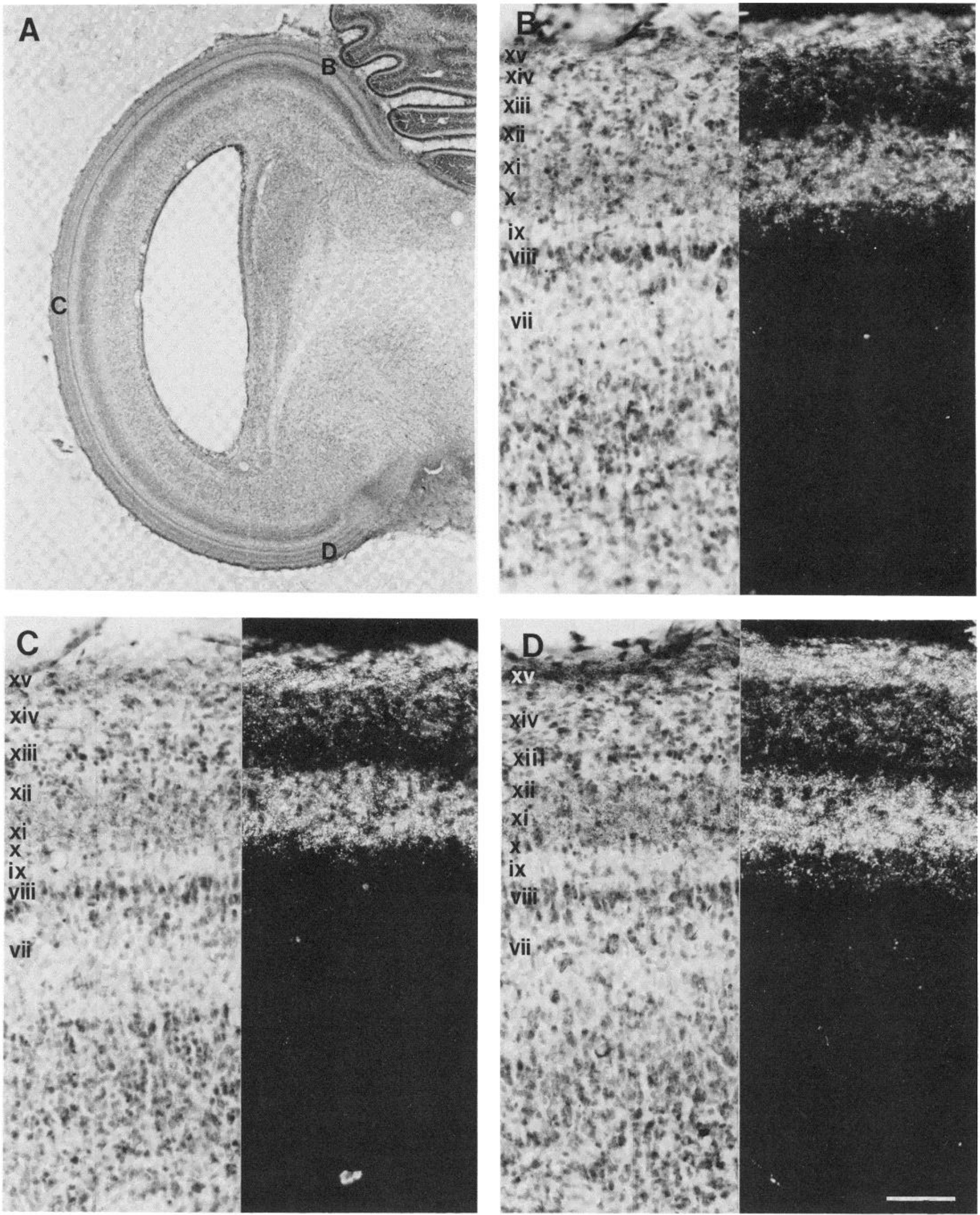

Figure 5. A, Low proper photomicrograph of a cresyl violet-stained section through the long axis of the tectum from an $\mathrm{E} 15 \mathrm{embryo}$. $B$ to $D$, Higher power brightfield and darkfield photomicrographs, approximately from the areas indicated in $A$, showig the HRP-labeled axons. It shows that the retinal axons have penetrated equally in all areas of the tectum. Bar, $50 \mu \mathrm{m}$. 

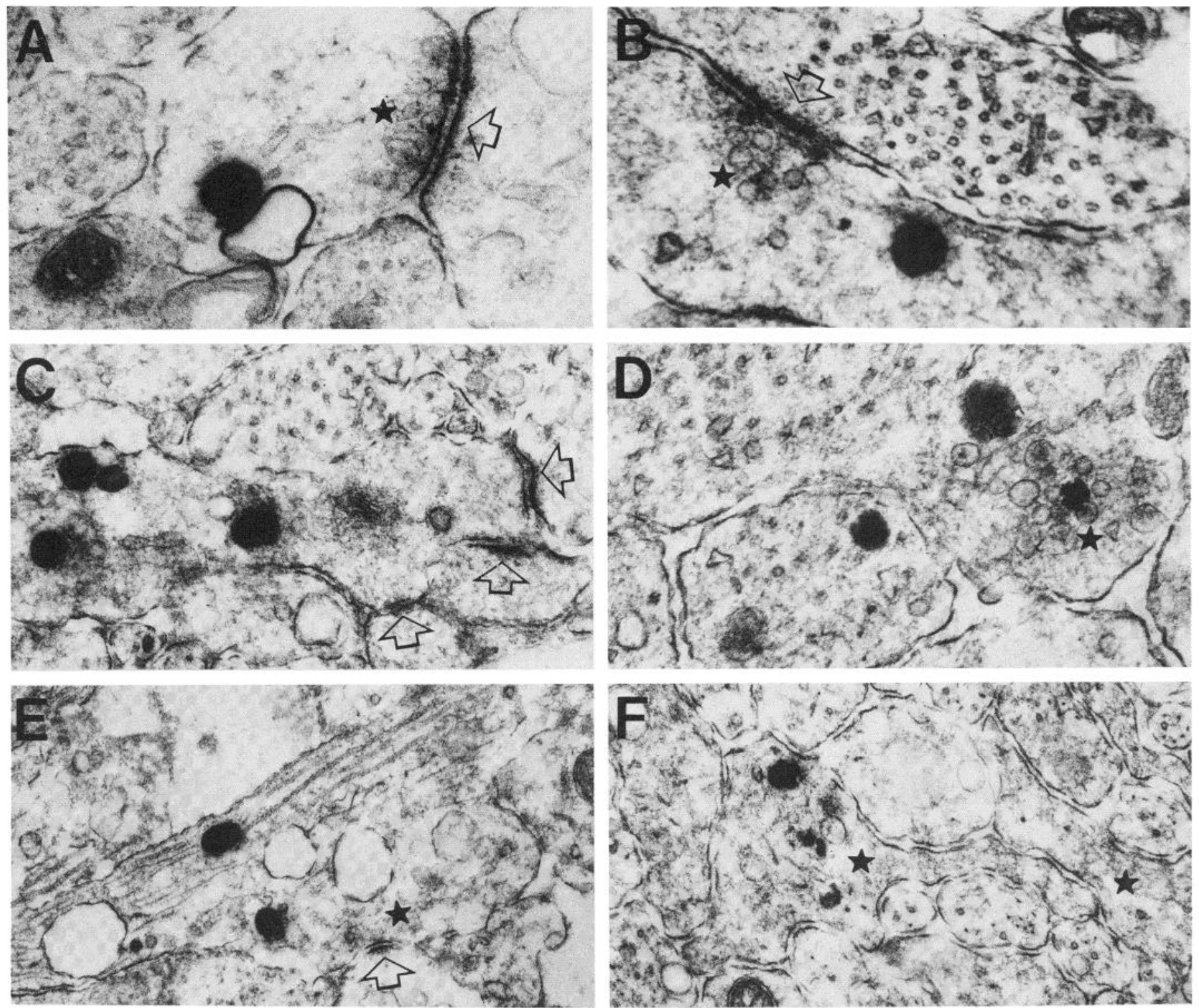

Figure 6. Electron micrographs from the rostral tectum of embryos showing HRP-labeled retinal axons and terminals. A, HRP-labeled profile (star) containing vesicles adjacent to a membrane density (arrow) in a process of a tectal cell. This is from an E7 embryo. Magnification $\times 70,000$. B, Profiles similar to that in $A$ but from an E9 embryo. Magnification $\times 70,000$. C, HRP-labeled profile forming membrane density junctional complexes with tectal cell processes but containing no obvious vesicles. Magnification $\times 49,500$. D. HRP-labeled profile (star) with a concentration of vesicles but not adjacent to an obvious membrane density. Magnification $\times 70,000$. E, An HRP-labeled axon which extended out of the picture toward the upper right and lower left corners. There is a swelling in the center of this axon which appears to be making a synaptic junction with a tectal cell (arrow). Magnification $\times 36,400$. $F$, Field of retinal axons at the lower extent of stratum opticum. Most axons are in cross-section. Two axons (stars) are approaching longitudinal section. The profile in the center has some characteristics of a growth cone. Magnification $\times 46,200$.

al., 1983) and where the first axons appear in the optic fiber layer (Goldberg and Coulombre, 1972). Since retinal synapses were found in rostral tectum as early as E7, and since only ganglion cells in central retina have axons in the tectum at this age, it can be concluded that ganglion cells in the central retina form the earliest retinotectal synapses with cells in the rostral tectum.

The implication of these results is that the early optic axons shift their connections in the tectum. In the mature chick the centrally positioned retinal ganglion cells project to the center of the tectum (DeLong and Coulombre, 1965; McGill et al., 1966; Crossland and Uchwat, 1979). In the early embryo, axons from central retina connect to rostral tectum. Since tectal cells are generated in a rostral-to-caudal pattern (LaVail and Cowan, 1971b), no new tectal cells will be added to the rostral tectum much after the first connections have formed. Thus, the early connections from central retina to rostral tectum could be broken and re-formed in a more central tectal location in order to arrive at the adult pattern of connections.

There are other possible ways to generate the adult pattern of retinotectal connections without invoking shifting connections. The data from the present study do not allow determination of the percentage of retinal axons which are forming synapses in the early tectum. It is possible that only a small percentage of the ganglion cells make connections early and that the majority continue to grow toward their proper (adult) position to terminate. Subsequently, ganglion cells which connected inappropriately could be eliminated by cell death (Rager and Rager, 1978; Hughes and McLoon, 1979). This would not necessitate a continual making and breaking of synapses. However, this possibility seems most unlikely in light of studies in other species.

Gaze et al. (1974), based on their studies in Xenopus, were the 
The Journal of Neuroscience

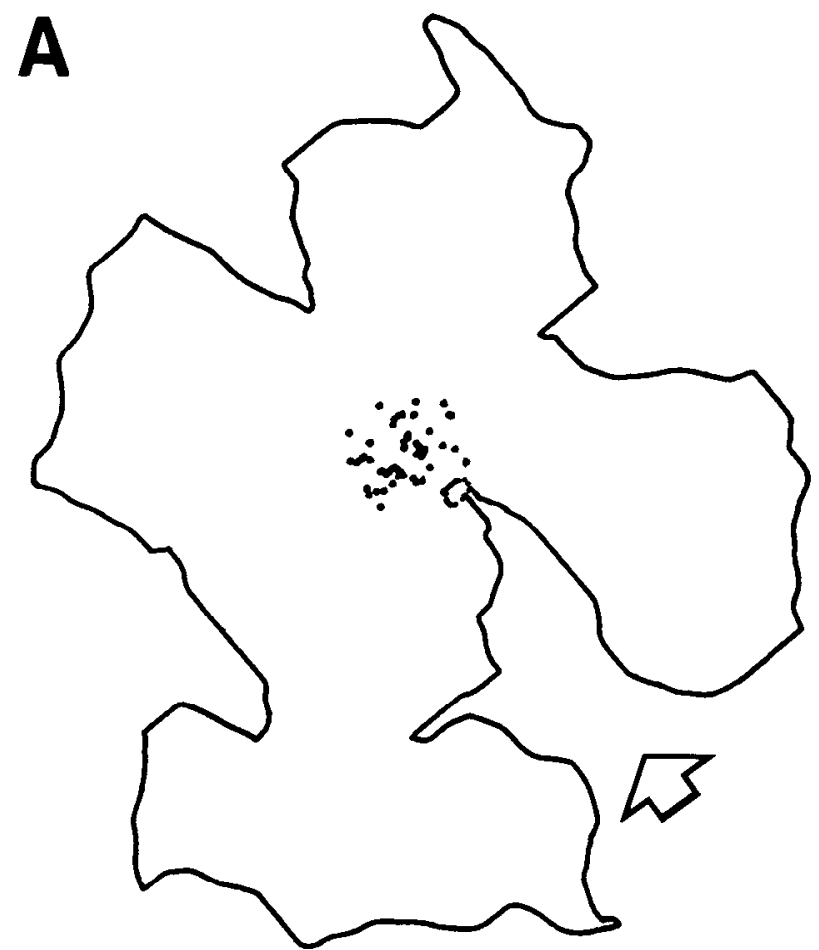

Shifting Retinotectal Connections

Figure 7. Plots of retinas from E7 $(A)$ and $E 8(B)$ embryos showing the distribution of FB-labeled cells resulting from injections of the dye into the tectum on E4. The arrows indicate the position of the optic fissure.

first to point out the mismatch in the patterns of development in the retina and tectum; that is, retina develops from central to peripheral and tectum develops from rostral to caudal. In Xenopus retinal axons arrive in the tectum and form functional connections before the entire retina or tectum is generated. Since a retinotopically ordered map exists in the tectum throughout its protracted development, Gaze et al. (1974) hypothesized that connections had to continually shift during development in order to maintain this pattern. Although this theory provided for a certain amount of controversy in the field (Jacobson, 1976, 1977), recent studies largely confirm this shift of connections during amphibian development (Gaze et al., 1979; Fraser, 1983; Reh and Constantine Paton, 1984). The goldfish, whose brain and retina grow throughout life, exhibits a similar disparity in the growth between these two structures (Meyer, 1978; Raymond and Easter, 1983). The detailed course of retinal axons in the goldfish tectum was examined and found to be consistent with the shifting connections hypothesis (Easter and Stuermer, 1984).

An optic axon shifting its position within its target nucleus may exhibit a mode of growth different from that of an optic axon growing to its target nucleus. The growth cones of retinal axons while in the retina (Krayanek and Goldberg, 1981; Halfter and Deiss, 1984) and in the optic tract (S. C. MCLoon, unpublished observation) appear tightly adherent to and often inserted in the external limiting membrane. ${ }^{4}$ At some point within its nucleus of termination the growth cone of the retinal axon is released from the external limiting membrane, and the axon begins to arborize and form connections. On E9 a new population of growing retinal axons appeared deep to stratum opticum. It is possible that this late-appearing group of axons consists of those which are in the process of shifting. If these are axons shifting their connections, it appears that this secondary growth does not necessitate growth along the external limiting membrane as did the initial growth to the tectum. Thanos and

\footnotetext{
${ }^{4}$ Usually, in the retina proper, this structure is called the inner limiting membrane; however, it has the same origin as, and is continuous with, the external limiting membrane of the brain.
}

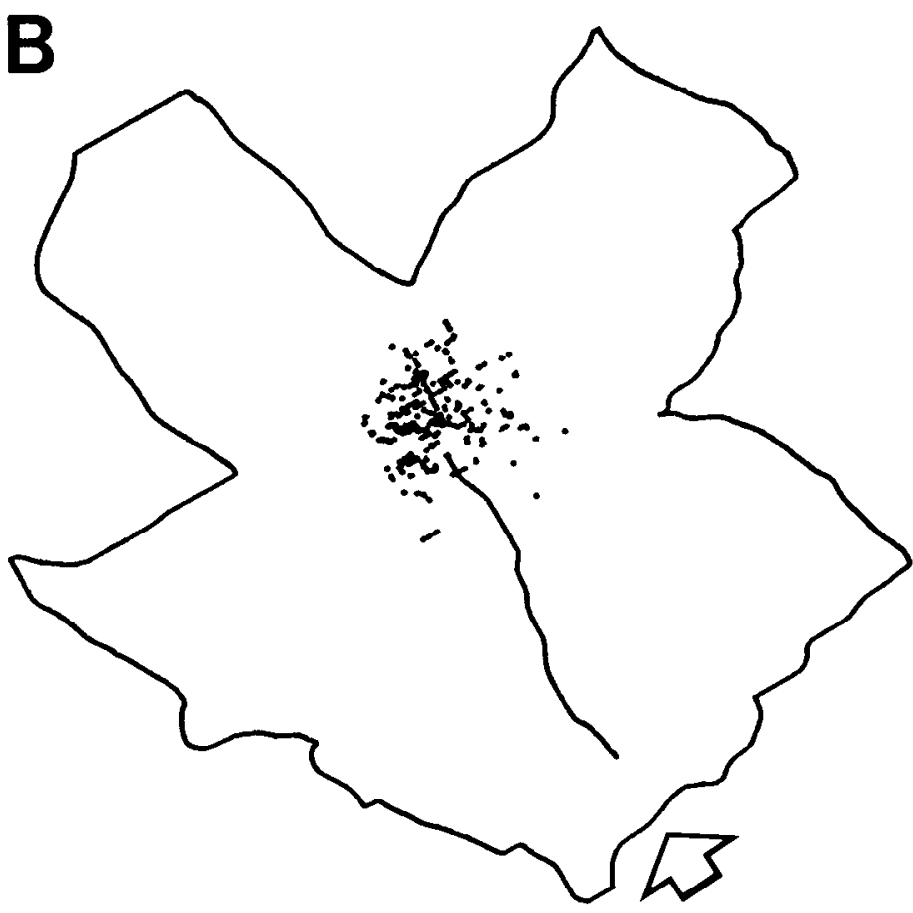

Bonhoeffer (1983) also described a late-appearing population of growing retinal axons deep to stratum opticum. They suggested that these were a population of axons which arrived to the tectum late rather than axons shifting connections.

It is unlikely that competition for synaptic space is solely responsible for initiating the shift in position of retinotectal connections during development. Partial retinal ablations have been made early in development such that the portion of the retina destined to innervate the rostral tectum is absent (Crossland et al., 1974). In this case, at the end of development, the rostral tectum is not innervated by the retina. This means that the retinal projection shifted from its early site of connection in rostral tectum cven in the absence of "competing" retinal axons to fill the vacated space.

The presence of shifting connections during development has important implications for theories on how the retinotopic pattern of retinotectal connections develops. Sperry (1963) postulated the existence of specific cytochemical markers on optic terminals and tectal neurons. A matching of the markers on the retinal terminals with the appropriate tectal cell markers would result in the specific pattern of connections between the retina and the tectum. The studies of Crossland et al. (1974) have shown that the retinal neurons are specified very early in development. That is, a change in the relative position of the retinal neurons to one another by retinal lesions did not alter their ultimate sites of termination in the tectum. The presence of sliding connections during development suggests that either the cellular markers continually change during development, that specific cellular markers do not exist, or that synapses must be formed in order for cellular markers to be sampled.

Theories have been proposed to account for the development of orderly retinotectal connections which do not require precise cytochemical markers. In one such theory, it was suggested that optic axons grow from the eye in an orderly fashion and maintain this order into the terminal field (e.g., Horder and Martin, 1979). There are many problems with this theory. For example, the early retinal projection to the tectum lacks topographic precision. The initial projection is only roughly ordered and then refined during subsequent development (McLoon, 1982b; Thanos and Bonhoeffer, 
1983). Orderly ingrowth of axons alone could not account for this refinement process. Also, as described above, in the absence of a portion of the retina, the remaining retinal projection still fills only the appropriate portion of the tectum. This suggests that some sort of polarity cue is present on the tectum. In all likelihood, a multiplicity of factors is involved in generating a topographically ordered map of retinal terminals on the tectum.

In surmirary, this study showed that retinal axons form synaptic connections almost as soon as they arrive in the tectum. The first connections appear to be in the area the axons enter the tectum, the rostroventral tectum, and they are formed by axons from ganglion cells in central retina. Since cells in this area of the retina project to central tectum in the mature visual system, and since cells are added predominantly to the caudal tectum, it is suggested that the early retinotectal connections shift during subsequent development.

\section{References}

Adams, J. C. (1980) Stabilizing and rapid thionir stainiry of TMB-based HRP reaction product. Neurosci. Lett. 17: 7-9.

Bonhoeffer, F., and J. Huf (1982) In vitro experiments on axon guidance demonstrating an anterior-posterior gradient on the tectum. EMBO J. 1: 427-431.

Crossland, W. J., and G. J. Uchwat (1979) Topographic projections of the retina and optic tectum upon the ventral lateral geniculate nucleus in the chick. J. Comp. Neurol. 185: 87-106.

Crossland, W. J., W. M. Cowan, L. A. Rogers, and J. P. Kelly (1974) Specification of the retino-tectal projection in the chick. J. Comp. Neurol. 155: $127-164$.

Crossland, W. J., W. M. Cowan, and L. A. Rogers (1975) Studies on the development of the chick optic tectum. IV. An autoradiographic study of the development of retino-tectal connections. Brain Res. 91: 1-23.

DeLong, G. R., and A. J. Coulombre (1965) Development of the retinotectal topographic projection in the chick embryo. Exp. Neurol. 13: 351-363.

Dunn, B. E., and M. A. Boone (1976) Growth of the chick embryo in vitro. Poult. Sci. 55: 1067-1071.

Dutting, D., A. Gierer, and G Hansmann (1983) Self-renewal of stem cells and differentiation of nerve cells in the developing chick retina. Dev. Brain Res. 10: 21-32.

Easter, S. S., Jr., and C. A. O. Stuermer (1984) An evaluation of the hypothesis of shifting terminals in goldfish optic tectum. J. Neurosci. 4: 1052-1063.

Fraser, S. E. (1983) Fiber optic mapping of the Xenopus visual system: Shift of the retinotectal projection during development. Dev. Biol. 95: 505-511.

Fujisawa, H., S. Thanos, and U. Schwarz (1984) Mechanisms in the development of retinotectal projections in the chick embryo studied by surgical deflection of the retinal pathway. Dev. Biol. 102: 356-367.

Fujita, S., and M. Horii (1963) Analysis of cytogenesis in chick retina by tritiated thymidine autoradiography. Arch. Histol. Jpn. 23: 359-366.

Gaze, R. M., M. J. Keating, and S. H. Chung (1974) The evolution of the retinotectal map during development in Xenopus. Proc. R. Soc. Lond. (Biol.) 185: 301-330.

Gaze, R. M., M. J. Keating, A. Ostberg, and S. H. Chung (1979) The relationship between retinal and tectal growth in larval Xenopus. Implications for the development of the retinotectal projection. J. Embryol. Exp. Morphol. 53: 103-143.

Gerfen, C. R., D. D. M. O'Leary, and W. M. Cowan (1982) A note on the transneuronal transport of wheat germ agglutinin-conjugated horseradish peroxidase in the avian and rodent visual systems. Exp. Brain Res. 48: 443-448.

Goldberg, S. (1974) Studies on the mechanics of development of the visual pathways in the chick embryo. Dev. Biol. 36: 24-43.

Goldberg, S., and A. J. Coulombre (1972) Topographical development of the ganglion cell fiber layer in the chick retina. A whole mount study. J. Comp. Neurol. 146: 507-518.

Halfter, W., and S. Deiss (1984) Axon growth in embryonic chick and quail retinal whole mounts in vitro. Dev. Biol. 102: 344-355.

Hamburger, V., and H. Hamilton (1951) A series of normal stages in the development of the chick embryo. J. Morphol. 88: 49-92.
Horder, T. J., and K. A. C. Martin (1979) Morphogenetics and an alternative to chemospecificity in the formation of nerve connections. Soc. Exp. Biol. 32: 275-358.

Hughes, W. F., and S. C. McLoon (1979) Ganglion cell death during normal retinal development in the chick: Comparisons with cell death induced by early target field destruction. Exp. Neurol. 66: 587-601.

Jacobson, M. (1976) Histogenesis of retina in the clawed frog with implications for the pattern of development of retinotectal connections. Brain Res. 103: $541-545$.

Jacobson, M. (1977) Mapping the developing retinotectal projection in frog tadpoles by a double label autoradiographic technique. Brain Res. 127: $55-67$.

Kahn, A. J. (1973) Ganglion cell formation in the chick neural retina. Brain Res. 63: 285-290.

Kahn, A. J. (1974) An autoradiographic analysis of the time of appearance of neurons in the developing chick neural retina. Dev. Biol. 38: 30-40.

Krayanek, S., and S. Goldberg (1981) Oriented extracellular channels and axonal guidance in the embryonic chick retina. Dev. Biol. 84: 41-50.

LaVail, J. H., and W. M. Cowan (1971a) The development of the chick optic tectum. I. Normal morphology and cytoarchitectonic development. Brain Res. 28: 391-419.

LaVail, J. H., and W. M. Cowan (1971b) The development of the chick optic tectum. II. Autoradiographic studies. Brain Res. 28: 421-441.

McGill, J. I. T. P. S. Powell, and W. M. Cowan (1966) The retinal representation upon the optic tectum and isthmo-optic nucleus in the pigeon. J. Anat. 100: 5-33.

McGraw, C. F., and B. J. McLaughlin (1980) Fine structural studies of synaptogenesis in the superficial layers of the chick optic tectum. J. Neurocytol. 9: 79-93.

McLoon, S. C. (1982a) Evidence for sliding connections in the development of the retinotectal projection in the chick. Soc. Neurosci. Abstr. 8: 451 .

McLoon, S. C. (1982b) Alterations in precision of the crossed retinotectal projection during chick development. Science 215: 1418-1420.

McLoon, S. C., and R. D. Lund (1982) Transient retinofugal pathways in the developing chick. Exp. Brain Res. 45: 277-284.

Mesulam, M. (1978) Tetramethyl benzidine for horseradish peroxidase neurohistochemistry. A non-carcinogenic blue reaction product with superior sensitivity for visualizing neural afferents and efferents. J. Histochem. Cytochem. 26: 106-117.

Meyer, R. L. (1978) Evidence from thymidine labeling for continuing growth of retina and tectum in juvenile goldfish. Exp. Neurol. 59: 99-111.

O'Leary, D. D. M., C. R. Gerfen, and W. M. Cowan (1983) The development and restriction of the ipsilateral retinofugal projection in the chick. Dev. Brain Res. 10: 93-109.

Rager, G. (1980) Development of the Retinotectal Projection in the Chicken, Springer-Verlag, Berlin.

Rager, G., and R. Kreische (1978) A current-source-density analysis in the developing optic tectum of the chickon. Nourosci. Lett. Suppl. 1: 394.

Rager, G., and U. Rager (1978) Systems-matching by degeneration. I. A quantitative electron microscopic study of the generation and degeneration of relinal yanglion cells in the chicken. Exp. Brain Res. 33: 65-78.

Rager, G., and B. von Oeynhausen (1979) Ingrowth and ramification of retinal fibers in the developing optic tectum of the chick embryo. Exp. Brain Res. 35: 213-227.

Raymond, P. A., and S. S. Easter, Jr. (1983) Postembryonic growth of the optic tectum in goldfish. I. Location of germinal cells and numbers of neurons produced. J. Neurosci. 2: 1077-1091.

Reh, T. A., and M. Constantine-Paton (1984) Retinal ganglion cell terminals change their projection sites during larval development of Rana pipiens. J. Neurosci. 4: 442-457.

Sperry, R. W. (1963) Chemoaffinity in the orderly growth of nerve fiber patterns and connections. Proc. Natl. Acad. Sci. U. S. A. 50: 703-710.

Thanos, S., and F. Bonhoeffer (1983) Investigations on the development and topographic order of retinotectal axons: Anterograde and retrograde staining of axons and perikarya with rhodamine in vivo. J. Comp. Neurol. 219: $420-430$.

Thanos, S., and F. Bonhoeffer (1984) Development of the transient ipsilateral retinotectal projection in the chick embryo: A numerical fluorescencemicroscopic analysis. J. Comp. Neurol. 224: 407-414. 